\title{
MOTIVAÇÃO E PRODUTIVIDADE: CONSIDERAÇÕES TEÓRICAS SOBRE A IMPORTÂNCIA DE UM BOM LÍDER NAS ORGANIZAÇÕES
}

\author{
Andrey Ferraz Carvalho', Silvana Maia Borges², Jonathan \\ Turchetti Bernardi ${ }^{3}$
}

\begin{abstract}
RESUMO: As mudanças sociais e tecnológicas demandam novas formas de organização, comunicação, bem como de liderar uma empresa. Além disso, para se ter trabalhadores dispostos e motivados é necessário, também, um líder motivado. Deste modo, o objetivo deste trabalho foi entender a influência da liderança na motivação de colaboradores, bem como seu impacto na produtividade das organizações. Para atingir tal propósito foi realizada uma pesquisa bibliográfica, qualitativa, de cunho exploratório, através da busca de publicações na SciELO, o que resultou no total de 73 artigos. Dentre estes materiais foram selecionados os artigos que retratavam a motivação nos processos de gestão e no bem-estar dos colaboradores, restando, após a identificação daqueles que não atendiam aos critérios de inclusão da pesquisa, sete artigos, os quais foram analisados e discutidos no estudo. Assim, verificou-se que a liderança e a motivação são fatores fundamentais para a produtividade e alcance de objetivos no trabalho. A liderança relaciona-se com a cultura organizacional, sendo percebido que um líder pode criar, manter ou mudar os tipos de cultura das organizações, conquanto que a cultura também molda aspectos do líder. Concluiu-se que a competitividade tem crescido e apenas resultados não bastam para o desenvolvimento de uma organização, é preciso que haja um ambiente motivador para que os colaboradores possam desempenhar suas atividades com maior empenho e engajamento, sem prejudicar sua saúde no trabalho.
\end{abstract}

Palavras-chave: Liderança; Motivação; Produtividade; Organizações.

Submissão: $10 / 01 / 2020$

Aceite: $28 / 09 / 2020$

DOI: 10.47591/RAC.2674-9203.2021v3n1.art2-14-22

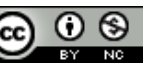

Este trabalho está licenciado com uma Licença Creative Commons Atribuição-NãoComercial 4.0 Internacional.

\footnotetext{
${ }^{1}$ Psicólogo pela Faculdade Integrada de Santa Maria - FISMA. E-mail: andreyferraz804@gmail.com

${ }^{2}$ Psicóloga pela Universidade Franciscana (graduação), Mestra em Educação pela Universidade Federal da Fronteira Sul, e atualmente docente da Faculdade Integrada de Santa Maria - FISMA. E-mail: silvana.borges@fisma.com.br

${ }^{3}$ Psicólogo pela Faculdade Integrada de Santa Maria - FISMA. E-mail: jturchetti.b@gmail.com
} 


\section{INTRODUÇÃO}

Nos últimos anos, o intenso avanço da globalização no mundo passou a modificar a maneira de se conduzir as organizações, bem como as pessoas que dela fazem parte. Chiavenato (2014a) aponta que, em função deste avanço tecnológico e da globalização, as novas formas de comunicação e a exigência por produtividade demandam um novo estilo de organização, um novo modo de liderar, assim como novas posturas dos executivos para sustentar a intensa competitividade. Outros sim, conforme Rothmann (2017), nas abordagens mais recentes de liderança (tais como a teoria de atribuição da liderança, a teoria da liderança carismática e a da liderança transformacional), os líderes são vistos como administradores do propósito, em vez de, meramente, influenciar os subordinados. Siqueira e Martins (2013) também destacam a importância que se tem dado para o bem-estar e saúde dos trabalhadores e a influência deste aspecto na produção e na vida dos mesmos.

Para que os trabalhadores estejam dispostos e motivados a desempenhar suas funções de acordo com os objetivos das organizações, Rothmann e Cooper (2017) consideram que é necessário ter um líder também motivado, uma vez que a liderança, conforme Chiavenato (2014b) é o fator que irá impulsionar uma organização no mundo da competitividade, além de influenciar o comportamento das pessoas que dela fazem parte. Com isso, esta pesquisa justifica-se por problematizar como a motivação se relaciona com os modos de gestão atuais, bem como sua influência na busca por resultados.

Considerando o extenso avanço da globalização e das tecnologias, que trouxeram consigo um contexto de alta produtividade e competitividade, sobretudo no mundo do trabalho, o objetivo deste estudo é, por meio de uma pesquisa bibliográfica, entender a influência da liderança na motivação de colaboradores, bem como seu impacto na produtividade das organizações. Logo, este trabalho visou responder: qual a influência da liderança na motivação dos colaboradores e na produtividade das empresas? Acredita-se que respondendo a tal questão será possível explicitar que um líder motivado e que motiva os colaboradores, especialmente no contexto atual, de grandes exigências e disputas, promoverá bemestar no local de trabalho. Em consonância, um ambiente motivador para os colaboradores, potencializa o rendimento de uma organização.

Para compor o artigo, primeiramente são apresentados os fundamentos teóricos que subsidiam a discussão, sendo contemplados os conceitos de motivação e liderança, de forma geral, bem como a relação entre tais temas. Em seguida são descritos os procedimentos metodológicos norteadores do estudo, o qual baseou-se em uma pesquisa bibliográfica. Finalmente, a discussão e análise dos resultados, que contempla uma análise abrangente dos artigos selecionados, em consonância com o objetivo proposto, apontando a importância do líder que reconhece e compreende a necessidade de motivar sua equipe, o que se refletirá na obtenção de resultados favoráveis às organizações. 


\section{REVISÃO TEÓRICA}

A motivação ${ }^{1}$ é primordial para as relações interpessoais, bem como para a busca de objetivos, produtividade e autodesenvolvimento no imenso campo das organizações. Tadeucci (2009) considera a motivação como um estado intrínseco que direciona as pessoas para determinados comportamentos, associando-a na busca por metas ou objetivos. Marques (2016) aponta a motivação como um processo onde esforços são combinados para mobilizar e sustentar comportamentos que objetivam atingir determinados resultados estabelecidos, sendo um processo pelo qual as pessoas são levadas a obter sucesso dentro das organizações ao passo em que seus objetivos são atingidos dentro do mercado de trabalho.

De acordo com Deci e Ryan (2000, apud SILVA, WENDT e ARGIMON, 2010), a motivação de um indivíduo apresenta-se em três níveis de satisfação, sendo eles: a necessidade de autonomia, a necessidade de sentir-se competente e a necessidade de relacionamentos e formação de vínculos. Ainda, para os autores citados, essas necessidades psicológicas básicas se manifestam de forma autônoma - onde a motivação interna é independente de reconhecimento externo - ou de forma controlada - quando acontece por uma regulação externa, seja por aprovação ou punição.

Para Gondim e Silva (2004) a motivação e o desempenho decorrem de diversos fatores interpostos como meios de mediação no ambiente de trabalho. Na sociedade, em geral, as organizações priorizam que as atividades sejam desempenhadas com qualidade e produtividade e, para isso, os autores consideram ser fundamental que a gestão da empresa compreenda a individualidade de cada colaborador, para assim entender de que forma será possível que este consiga atingir o máximo possível de seu potencial dentro do trabalho.

Segundo a pesquisa de Echeveste et al. (1999), o perfil mais adequado para os executivos dentro do mercado de trabalho em empresas multinacionais abarca a capacidade de liderança, motivação, habilidades interpessoais e coordenação de trabalho em equipe. Isso revela a importância atribuída à liderança e as características do líder para o desenvolvimento das organizações, assim como para a gestão dos colaboradores que dela fazem parte.

Já a liderança, para Rothmann (2017), é a capacidade de influenciar um grupo na direção da realização de objetivos, sendo que, em geral, refere-se a técnicas de influência não coercitivas, ou seja, a liderança é persuasão, e não dominação. Segundo o autor, a liderança envolve um processo de influência, ocorrendo apenas

\footnotetext{
${ }^{1}$ Segundo Rothmann (2017), existem várias teorias que buscam explicar o fenômeno da motivação. As primeiras teorias da motivação foram a teoria da hierarquia de necessidades de Maslow, a teoria de dois fatores de Herzberg, a Teoria X e a Teoria Y de McGregor e a teoria das necessidades de McClelland. Já as teorias contemporâneas são a teoria da equidade, a teoria da expectativa, a teoria de definição de objetivos, a teoria da autodeterminação, a teoria do engajamento, a teoria da autoeficácia e a teoria do reforço. Tais teorias buscam explicar o que motiva as pessoas. Este estudo não tem como foco aprofundar teorias sobre liderança. Porém, cabe registrar que, conforme Rothmann (2017), diversas teorias já foram elaboradas para explicar a liderança. Essas teorias podem ser estudadas, de forma geral, em razão de quatro abordagens: as teorias do traço de personalidade, as teorias comportamentais, as teorias da contingência e as teorias recentes (incluindo perspectiva de atribuição, liderança carismática e liderança transacional e transformacional).
} 
quando os indivíduos se dispõem a adotar os objetivos do grupo como sendo seus próprios objetivos. Dessa forma, a liderança se centra na construção de equipes coesas e voltadas para objetivos. Complementando:

Em conformidade com os avanços em comportamento organizacional positivo, as pesquisas mostraram que a liderança positiva (isto é, clima positivo, relacionamentos positivos, comunicação positiva e propósito positivo) e a autenticidade dos líderes têm um papel importante no desempenho do trabalho e na retenção de funcionários (ROTHMANN, 2017, p. 132).

Na percepção de Rothmann e Cooper (2017) pode-se ver diversos pontos cruciais acerca de uma boa liderança dentro das empresas e organizações, levando em conta que é papel do líder organizar o esforço coletivo dos colaboradores que fazem parte de uma empresa. Os autores consideram que uma boa liderança acarreta o sucesso organizacional e o bem-estar das pessoas que dela fazem parte. Além disso, estes autores referem liderança como um dos fatores associados ao desempenho e à satisfação dos subordinados, uma vez que um bom líder exerce papel fundamental na compreensão dos comportamentos individuais e/ou do grupo organizacional, considerando que é ele quem direciona a organização e os colaboradores para a realização dos objetivos.

Ainda, Rothmann (2017) indica que a qualidade da supervisão e gerência é um componente importante para a criação de um ambiente motivacional. A maioria dos supervisores e gestores têm entendimento restrito de sua influência no engajamento do trabalho, no compromisso e/ou nas intenções de permanecer ou não na organização. Uma tarefa importante dos gerentes, por conseguinte, é otimizar o clima emocional de suas equipes e melhorar o engajamento dos colaboradores. Deve-se registrar também que, conforme o autor, uma pessoa pode assumir um papel de liderança devido à posição que ocupa na organização. Entretanto, nem todos os gestores são líderes e nem todos os líderes são gestores. Como explica o autor em questão, a maioria dos especialistas concorda que líder e gestor/administrador são papéis distintos. Porém, um administrador é uma pessoa que assume um papel gerencial que consiste em atividades como planejamento, processamento de informações, organização, controle e comunicação com clientes ou fornecedores. Esses gestores serão líderes quando exercerem influência sobre seus subordinados, visando alcançar os objetivos organizacionais. Para tanto, esses líderes terão que atuar de forma a motivar seus colaboradores.

A literatura de Rothmann e Cooper (2017) aponta também para diferentes teorias de motivação, desde as clássicas até as atuais. Dentre elas estão, por exemplo, a teoria do traço, a comportamental, da contingência, a liderança situacional e a teoria de troca entre líder-membro no ambiente de trabalho. Conforme, os autores, pode-se formar um local motivador para os colaboradores assegurando que seus motivos e valores coincidem com os da organização. Além disso, é importante que o desempenho dos colaboradores seja facilitado por meio de um ambiente favorável e também pelo uso de recompensas e disciplina apropriadas. De acordo com esses autores, um ambiente em que os colaboradores se sentem recompensados por suas atividades gera maior índice de satisfação e produtividade. 


\section{MÉTODO}

Esta pesquisa consistiu, conforme Gil (2010), em uma pesquisa de abordagem qualitativa, visto que não foram utilizados métodos estatísticos para o levantamento e análise dos dados. Em relação aos seus objetivos, caracterizou-se por ser de cunho exploratório que, segundo o autor citado, consiste em proporcionar maior familiaridade com o problema estudado, com intuito de explicitá-lo, proporcionando maior número de informações sobre o tema investigado, abarcando um planejamento mais flexível.

Ainda a respeito da classificação da pesquisa, esta se baseou em procedimentos bibliográficos. Uma pesquisa bibliográfica, de acordo com Gil (2010), é elaborada com base em materiais já publicados, como por exemplo, livros e artigos científicos. Para o autor, esse tipo de pesquisa é vantajoso por proporcionar o acesso a um grande número de dados acerca do fenômeno estudado.

Para o desenvolvimento da pesquisa optou-se por realizar uma busca das publicações na base de dados ScientificElectronic Library Online (SciELO), utilizando as seguintes combinações de palavras-chave: motivação AND gestão de empresas; motivação AND liderança. Esta plataforma foi escolhida em razão de ser uma biblioteca digital de livre acesso e modelo cooperativo de publicação digital de periódicos científicos. Consideraram-se como critérios de inclusão artigos publicados no idioma português, que possuíssem pelo menos uma das palavraschave utilizadas nas buscas, sendo selecionados aqueles que retratavam, especificamente, a motivação nos processos de gestão e no bem-estar dos colaboradores, em consonância com o objetivo do estudo. Registra-se também que não foi delimitado um período para a seleção dos materiais. A busca na base de dados resultou em um total de73 artigos (sendo lido o resumo de todas estas publicações) e a partir dos critérios de inclusão foram selecionados sete artigos que foram lidos na íntegra, uma vez que apenas estes abordavam a motivação nas organizações, bem como aspectos acerca do líder das mesmas.

Após a organização do material a ser usado na pesquisa, adotaram-se formas de leituras conforme Gil (2010), objetivando identificar as informações e dados contidos no material selecionado, relacionando as informações e os dados com o problema proposto. Para isso foram utilizados quatro métodos de leitura: leitura exploratória, seletiva, analítica e interpretativa. Inicialmente, foi tomada uma visão global, por meio da leitura exploratória, com objetivo de identificar a utilidade do material para a realização da pesquisa. Seguindo a organização do material, a leitura seletiva visou, de acordo com o autor, estabelecer quais materiais de fato interessavam à pesquisa, sendo esta uma leitura mais aprofundada, de natureza crítica, porém objetiva.

Com a seleção dos textos já realizada, foi feita uma leitura analítica com intuito de ordenar e sintetizar as informações incluídas nas fontes bibliográficas. Tal leitura possibilitou a obtenção de respostas ao problema de pesquisa. Esta difere das demais por ser uma leitura imparcial. Por fim, Gil (2010) estabelece como a última etapa deste processo de leitura das fontes bibliográficas, a leitura interpretativa. Nesta, com o objetivo de correlacionar as hipóteses com o problema 
de pesquisa, o autor fixa-se nos dados obtidos, interligando-os com outros conhecimentos.

\section{DISCUSSÃO E ANÁLISE DOS RESULTADOS}

Ao considerar-se que todo avanço tecnológico e científico tornou o mundo mais globalizado com o passar dos anos, tem-se um deslocamento da economia mundial da área agrícola para a industrial. Pestana et. al (2003) referem-se à economia do conhecimento, sendo que o acesso à informação tem permitido a dominação ou o desenvolvimento de setores no interior das organizações. Neste contexto, os autores ainda ressaltam a crescente preocupação com as pessoas no ambiente de trabalho, tema que vem ganhando cada vez mais espaço na gestão das empresas. A ênfase passa a ser dada não só para a produtividade, mas também para as pessoas que das organizações fazem parte.

Com isso, Pestana et. al (2003) destacam a importância da liderança como fator primordial para a produtividade, assim como para a influência, comunicação e alcance de objetivos no trabalho em equipe. Para tanto, é essencial que as organizações contem com um gestor motivado e que promova bem-estar, eficiência e eficácia nas tarefas exercidas pelos colaboradores, gerando mais entusiasmo e prazer.

Machado, Cabral e Vaccaro (2018) realizaram um estudo transversal aplicando uma escala de motivação no trabalho, em uma amostra de 256 indivíduos, para entender a percepção de fatores motivacionais de colaboradores de organizações de tecnologia da região sul do Brasil. Os achados dos autores apontam para diferentes fatores motivacionais conforme a faixa etária dos colaboradores entrevistados, além de estarem relacionados com as relações entre colaboradores, sentimento de autonomia, competência e motivação para aprendizagem. Visto isso, os autores consideram que para a promoção da motivação nas empresas, deve-se alinhar os níveis estratégicos hierárquicos com a cultura organizacional das organizações, enfatizando o desenvolvimento interno de líderes. Já que, para estes autores, o papel da liderança influencia fortemente a satisfação dos colaboradores das empresas ao promover um ambiente apto para o desenvolvimento pessoal por meio de relações saudáveis, realização de objetivos coletivos, satisfação no trabalho de equipe e incentivo à cooperação. Entende-se então que a presença de um líder motivado dentro das organizações é capaz de acarretar engajamento, bem-estar e qualidade de vida no trabalho, potencializando assim a entrega de resultados mais produtivos para as mesmas.

Levando em conta que a motivação tornou-se aspecto chave para a produtividade das empresas, Ferreira et. al (2006) desenvolveram uma escala para avaliar índices de motivação nas organizações. Por existirem diversas teorias focadas na motivação, os autores citam que ela pode ser usada para a organização do trabalho, como realização e poder, focada no desempenho dos colaboradores ou no envolvimento destes com as tarefas.

Já Barreto et. al (2013) correlacionaram a liderança com a cultura organizacional, levando em conta que um líder pode criar, manter ou mudar os tipos de cultura das organizações, ao passo que a cultura da empresa também pode moldar os aspectos do líder. De acordo com os autores, os líderes podem fornecer mecanismos para o desenvolvimento da cultura organizacional ou os seus próprios 
comportamentos podem se tornar símbolos desta. Considerando a cultura uma variável que pode ser utilizada para a aplicação de estratégias e direcionar o rumo das empresas com mais efetividade, o desempenho é fruto dos valores e crenças compartilhados pelos membros das empresas.

Estes autores ainda salientam que, para a mudança de cultura, os líderes devem estar atentos aos conservadorismos refletidos nas crenças, valores e rituais próprios da organização, os quais podem dificultar as mudanças desejadas. Além disso, neste estudo de Barreto et. al (2013), pode-se ver que quanto maior a distância organizacional entre os líderes e os liderados (como, por exemplo, com a multiplicação de níveis hierárquicos), menor é a influência da liderança na cultura.

Dall'Agnol et. al (2013) realizaram um estudo com intuito de analisar as contradições e ambiguidades que atravessam a motivação de enfermeiros para exercer cargos de liderança em um hospital universitário. Neste estudo, os autores referem à liderança como um fenômeno grupal, uma vez que a forma com que o líder se comporta e articula as suas ações na organização reflete diretamente no processo de trabalho e engajamento da equipe. Deve-se considerar também a constatação de que relações de confiança e respeito entre os membros da equipe auxiliam na valorização do capital social dentro das organizações, além de fortalecer redes cooperativas e solidárias. Contudo, para isto, é preciso se ter um líder que cative e que promova a comunicação e o bom relacionamento entre os membros da equipe.

Desse modo, percebe-se que os achados do estudo em questão estão em sintonia com as teorias de liderança mais recentes, conforme as citadas por Rothmann (2017), nas quais os líderes são vistos como administradores do propósito e não apenas como influenciadores dos subordinados.

Ainda, em Dall'Agnol et. al (2013) encontra-se a diferenciação das práticas do líder e do chefe. Enquanto que o primeiro trata-se de alguém que ajuda, ouve, colabora na rotina de trabalho, desempenhando um papel mais afetivo e compreensivo, o segundo, tem um papel centrado no controle e comando, destacando um estilo gerencial mais autoritário, rígido e inflexível. Os resultados deste estudo ainda mostraram ser condição essencial para a prática da liderança o autoconhecimento, já que esse aspecto possibilita reconhecer as próprias habilidades (do líder) e dos demais colaboradores, assim como identificar as fragilidades individuais e coletivas, objetivando superá-las. Aqui é possível notar, reforçando a visão exposta por Rothmann (2017), a diferença entre líder e gestor/administrador, o que refletirá na motivação da equipe e, consequentemente, no desempenho da mesma.

Lopes, Moretti e Alejandro (2011) realizaram um estudo com uma equipe de vendas acerca da relação do sentimento de justiça no ambiente de trabalho, estes intermediados pela motivação, lealdade e intenção de turnover. Os resultados mostraram que os sentimentos de justiça têm forte correlação com a manutenção da estabilidade das equipes de vendas nas empresas estudadas. Os autores evidenciaram que a justiça distributiva e a interpessoal estavam altamente vinculadas com a manutenção e estabilidade das equipes de vendas. Os autores também salientam a importância de um bom ambiente de trabalho, onde seja possível o gestor reforçar o compromisso dos colaboradores enquanto equipe. Estes são dados que corroboram com a importância de se ter um líder motivado, capaz de 
gerir equipes e levar em conta os aspectos interpessoais no relacionamento, entre os colaboradores e chefias, dentro das organizações.

Por fim, Meirinhos e Barreto (2018) consideram que a motivação tem sido considerada como um dos meios para melhorar o desempenho das pessoas assim como das organizações as quais fazem parte, uma vez que se relaciona tanto com a produtividade quanto com a saúde organizacional. Além disso, segundo os autores, é de crucial importância que os líderes estejam atentos aos fatores motivacionais dos colaboradores de uma empresa, com intuito de identificar as condições necessárias para que estes a desempenhem com máximo potencial, levando em conta que um colaborador altamente motivado irá realizar seu trabalho de forma intensa, visando alcançar suas metas pessoais e organizacionais. Visto isso, entendese que é por meio do líder que será possível produzir mudanças nas atitudes e comportamentos dos indivíduos dentro de uma organização, proporcionando maior compromisso com os objetivos da mesma. Os autores ressaltam a importância de um líder transformacional, uma vez que este promove à mudança dos colaboradores, desenvolvendo a consciência dos liderados, a justiça, a igualdade, o humanismo e a liberdade entre os relacionamentos estabelecidos com os colaboradores.

\section{CONSIDERAÇÕES FINAIS}

Tem sido notável os avanços tecnológicos e juntamente, com isso, os processos de globalização que vem ocorrendo no mundo. Junto a este fenômeno, Chiavenato (2014a) aponta para um contexto de competitividade e exigência por produtividade cada vez maior e, focar apenas nos resultados da empresa, não é mais a única preocupação de um executivo, gestor ou líder. Estar atento para as relações interpessoais dentro das organizações, promover um ambiente de trabalho agradável, motivador e capaz de proporcionar bem-estar e qualidade de vida para os colaboradores, é fator indispensável para o bom rendimento de uma equipe, bem como para a produtividade organizacional.

Por meio dos resultados encontrados pode-se notar a importância da promoção de diálogo, trocas e cooperação do grupo por parte do líder, já que estas práticas possibilitam romper com velhos padrões de gestão e estruturas hierárquicas, sustentadas em práticas impositivas. Este é um dos aspectos fundamentais do papel da liderança para se promover um clima organizacional mais saudável e motivador, que incentive os colaboradores a alcançarem seus objetivos, assim como possibilita um ambiente que os motiva, a irem em busca destes.

Tem-se assim, a clara importância das pessoas enquanto seres dotados de sentimentos, emoções e subjetividade e juntamente com isso, o crucial papel da gestão de pessoas dentro de todas as organizações, assim como dos processos de liderança. Apenas produzir não é mais a única preocupação das empresas, estas devem se tornar espaços de crescimento profissional e pessoal.

Cabe expor, por fim, que o estudo apresentou como limitação a busca e seleção de artigos científicos para embasamento teórico em apenas um banco de dados, além de considerar artigos apenas no idioma português. Sendo assim, recomenda-se que pesquisas futuras possam ser feitas para aprofundar tal tema, 
realizando uma maior coleta de dados, considerando especialmente estudos empíricos sobre liderança e motivação nas organizações.

REFERÊNCIAS

BARRETO, L. M. T. S. et. al. Cultura organizacional e liderança: uma relação possível? São Paulo: Ver. Adm., 2013, v.48, n.1, p.34-52, jan./fev./mar.

CHIAVENATO, I. Gestão de Pessoas: o novo papel dos recursos humanos nas organizações. 4. ed. São Paulo: Barueri, 2014 (a).

CHIAVENATO, I. Comportamento organizacional: a dinâmica do sucesso das organizações. 3. ed. Barueri, SP: Manole, 2014 (b).

DALL'AGNOL, C. M. et al. Motivações, contradições e ambiguidades na liderança de enfermeiros em cargo de chefia num hospital universitário. Rev. Latino-Am: 2013, Enfermagem set.-out.;21(5): [07 telas]

ECHEVESTE, S. et. al. Perfil do Executivo no Mercado Globalizado. RAC: 1999, v. 3, n. 2, Mai./Ago., p.167-186.

FERREIRA, A. et. al. Construção e validação de uma Escala Multi-Factorial de Motivação no Trabalho (Multi-Moti). Comportamento organizacional e gestão, 2006, v. 12, n. 2, p. 187-198.

GIL, A.C. Como elaborar projetos de pesquisa. - 5. ed. São Paulo: Atlas, 2010.

GONDIM, S. M. G.; SILVA, N. Motivação no trabalho. In: Psicologia, Organizações e Trabalho no Brasil. Porto Alegre: Artmed, 2004, p. 145-176.

LOPES, E. L; MORETTI, S. L. A; ALEJANDRO, T. B. Avaliação de justiça e intenção de turnover em equipes de vendas: teste de um modelo teórico. São Paulo: ERA, 2011, v. 51, n. 6, nov/dez. p.553567

MACHADO, C. L. S.; CABRAL, P. M. F. e VACCARO, G. L. R. Segmento de Tecnologia Analisado pela Multidimensional WorkMotivationScale. RAC, Rio de Janeiro, v. 22, n. 3, art. 2, pp. 336-354, maio/junho 2018.

MARQUES, J.C. Comportamento organizacional. São Paulo: Cengage Learning Edições Ltda, 2016.

MEIRINHOS, R.; BARRETO, A. M. A Comunicação Estratégica como Fator de Retenção de Recursos Humanos. Media \& Jornalismo. v. 18, n. 33. Lisboa, nov. 2018.

PESTANA, M. C. et al. Desafios da sociedade do conhecimento e gestão de pessoas em sistemas de informação. Brasília: Ci. Inf., 2003, v. 32, n. 2, p. 77-84, maio/ago.

ROTHMANN, I. Fundamentos de psicologia organizacional e do trabalho. Ian Rothmann, Cary L. Cooper; tradução Luiz Claudio de Queiroz. 2. ed. Rio de Janeiro: Elsevier, 2017.

ROTHMANN, I.; COOPER, C. L. Psicologia Organizacional e do Trabalho. 2. ed. Rio de Janeiro: Elsevier, 2017.

SILVIA, M. A.; WENDT, G. W.; ARGIMON, I. I. L. A teoria da autodeterminação e as influências socioculturais sobre a identidade. Belo Horizonte: Revista em Psicologia, 2010, v. 16, n. 2, p. 351369.

SIQUEIRA, M. M. M.; MARTINS, M. C. F. Promoção de saúde e bem-estar em organizações. In: 0 Trabalho e as Organizações. Porto Alegre: Artmed, 2013,p.619-643.

TADEUCCI, M. S. R. Motivação e Liderança. Curitiba: IESDE Brasil S.A, 2011. 